\title{
TEXTOS Y GLOSAS Freud y la religión obsesiva
}

\section{INTRODUCCIÓN}

El objetivo del presente trabajo es estudiar el artículo de Freud "Los actos obsesivos y las prácticas religiosas" (1907) desarrollando las intuiciones que en él se encuentran. No es mi intención hacer un estudio del estado del pensamiento freudiano en esa época, donde, por ejemplo, todavía no se ha desarrollado el concepto de superyó, tan interesante para la comprensión de las neurosis obsesivas. Más bien deseo partir de ese artículo (y otros que iré citando) para sacar provecho de las ideas que allí se encuentran.

Quisiera centrarme en el cristianismo y comprobar la utilidad de acceder a la interpretación del mismo desde la categoría patológica de la obsesión sin que mi intención sea reducirlo a una neurosis obsesiva. Creo, sin embargo, que una cierta manera de vivirlo facilita la cristalización de los aspectos obsesivos de las personas. Pero también pienso que no es la única categoría útil en el análisis psicológico porque el cristianismo no es vivido de la misma manera por todos.

Al menos dos cosmovisiones diferentes han convivido en su seno y pueden encontrar igualmente justificación en el nuevo testamento: una perspectiva profesa el optimismo de exaltación mística y la otra es severamente enjuiciadora, restrictiva y proclive al dualismo pesimista. La primera cree en una liberación del mundo anunciada en Cristo, una reunión de todo en él. Se destaca el aspecto inclusivo de la redención, la inmanencia de Dios en toda la creación y la alegría y libertad responsable de la fe cristiana. La segunda insiste en la alienación del hombre y el mundo respecto de Dios. Acentúa la índole ultramundana de la redención, la inhibición de las actividades mundanas, la salvación limitada a los fieles y la importancia de la ortodoxia.

Ambos aspectos se dan en tensión mutua. Para los primeros la liberación ha comenzado, la nueva creación está en marcha. La peculiar sensación de alegría cósmica y agradecimiento del cristianismo primitivo deriva de que, con Cristo, Dios vuelve al hombre. El tiempo de gozar ha llegado. El segundo polo insiste en que la revelación es una batalla entre el bien y el mal cuya superación no está asegurada. Parte del NT exige vigilancia y rectitud moral 
a la espera de Cristo ante los peligros que se han de afrontar. La redención se sitúa en el futuro y la acción de Dios es externa. La sensación de triste espera, la adhesión a la ley, el intento de preservar una minoría pura contra un medio hostil, la expectativa de castigo... eran elementos judios que resurgían en el cristianismo. En su forma extrema el dualismo insiste en la indignidad de la humanidad, se inculca un acusado sentido del pecado y culpa y el cumplimiento estricto de la ley. El dios poderoso y despiadado del AT se encarna en el Cristo Juez. La iglesia asumió durante mucho tiempo la función judicial con considerable autoridad cultural. La idea de unión mística retrocedía en favor del concepto jurídico de obediencia estricta. La relación de hijo culpable a padre severo ensombreció la idea de reconciliación en Dios.

Para la primera cosmovisión el cisma entre lo humano y lo divino está salvado. Dios se unió al hombre para que éste se uniera a Dios. Así Cristo inaugura la transformación del hombre, su divinización. La debilidad humana se convierte en ocasión de la manifestación de Dios (Oh, felix culpa...!). Todo mal es una preparación para la redención. La resurrección anuncia la victoriosa reunión final de todo en Cristo. El mundo no es una prisión maligna sino el vehículo portador de la gloria de Dios, la matriz de la deificación. La semilla divina ya está en el mundo actuando y llevándolo a la perfección, por ello la historia se convierte en un camino hacia Dios. Lo divino es gloriosamente inmanente y activo en el hombre y su historia.

Pablo percibió los peligros de esta concepción enseñando un dualismo parcial con vistas a una futura unidad cósmica, pero temió que el exceso de entusiasmo resultara perjudicial. La lucha contra la abrumadora presencia del mal es la preocupación principal. Para reconocer la presencia de Dios se hace necesario retirarse de este mundo. El Cristo sufriente constituido en ejemplo moral sustituye al Cristo resucitado portador de salvación. El mundo no sólo no parece experimentar cambios sino que crucificó a Jesús y selló su pecaminosidad. La esperanza reside en el más allá y en el baluarte de la Iglesia. Pocos se han de salvar y por ello el esfuerzo ha de ser especialmente intenso. El cristiano no es divinizado sino convertido en justo ante Dios por un especie de sentencia. Pero por sí mismo sería incapaz ya que está intrínsecamente impregnado de pecado.

Así la experiencia de Dios podía oscilar entre la sublime relación de amor (romance divino) y un antagonismo punitivo y de condena jurídica. Esperanza y fe conviven con culpa y temor. La relación entre ambas cosmovisiones y su mútua interpenetración ha sido compleja pero parece indudable que la concepción dualista y pesimista ha sido predominante. Creo que es esta versión del cristianismo la que propicia una actitud psicológica que penetra en el ámbito de la neurosis obsesiva tal como lo supone Freud. Sin embargo 
la otra corriente, en la que cabe incluir a los místicos, facilitaría la aparición de las patologías del deseo y el amor. Su estudio partenecería a una examen de la erótica en la religión. Para ella valdría la categoría de la histeria.

Quisiera, antes de entrar en el tema, dedicar unas líneas al examen del deseo religioso como aspiración a la vínculación amorosa con Dios. No cabe duda de que las diferentes maneras de vivir la religión han de proceder de estructuras psicológicas profundas y subyacentes. Si hay una patología del deseo, los significantes religiosos prestan su terreno al desplazamiento: permiten una resolución parcial del conflicto pero al mismo tiempo lo mantienen inconsciente y le dan argumentos.

El deseo es la aspiración a colmar un vacío y la fuerza que empuja a conquistar el objeto del cual se espera que suprima la falta y confiera apaciguamiento. Pero el deseo se moldea por las incripciones históricas que constituyen los recuerdos de los placeres perdidos en el pasado y las frustraciones experimentadas. La primera carencia es el hambre y la sed y el seno materno el primer objeto de placer y apaciguamiento. Esta primitiva experiencia de carencia y satisfacción imprime en el psiquismo una huella indeleble. Todo objeto de amor posterior es de alguna manera el primer objeto perdido y recuperado, la madre. A esta forma del deseo el psicoanálisis le da el nombre de oralidad.

El estadio oral marca todo deseo. Comporta una actitud pasiva de acogida, un deseo de cuidados, de calor afectivo, de avidez amorosa, de confirmación narcisista de sí mismo por la incondicional disponibilidad de la madre... El deseo oral huye de los conflictos, de la lucha con la dura realidad y busca el objeto que da la satisfacción ilimitada a los deseos del niño interno. La búsqueda de calor y refugio en un vínculo íntimo total rigen la vida marcada por la oralidad. Dios es el objeto de transferencia de estos deseos lo que supone una acentuación de los rasgos maternos de la divinidad y una disminución de sus funciones paternas de exigencia, juez, ley, que son vividas como distancia. Se acentúan las connotaciones que favorecen el vínculo total, la subsunción en él, la satisfacción de necesidades, el autoengrandecimiento imaginario, la inflacción del propio yo que puede llevar al delirio de autodivinización. En mayor o menor proporción muchos de estos rasgos son reconocibles en la mística, también en muchos grupos sectarios. Toda religiosidad que acentúa los elementos de fusión con la divinidad, la unión con el todo, con la madre tierra, puede situarse en la órbita de la oralidad. Se privilegia la comunicación sensible, lo emocional primitivo, la simbólica materna. Sin el padre no hay tiempo, ni realidad exterior, ni ley humana, ni identidad sexual (problema clave en la histeria). Se potencian las sensaciones próximas a las que vive el niño en un contexto de relaciones fusionales, animistas y mágicas. La explo- 
sión emocional provoca la marginación del lenguaje y el pensamiento, la fusión no permite la necesaria distancia para que ambos se constituyan. Hoy puede hablarse de una recuperación de lo religioso bajo este signo y de un desfallecimiento de la función paterna. Es el caso de los grupos carismáticos, comunidades emocionales, sectas, de la llamada religiosidad light.

La histeria es la estructura de acogida para el deseo religioso así entendido. De hecho fue el psicoanálisis el que estableció el predominio de la oralidad en las estructuras histéricas. Dado que mi intención no es entrar a fondo en la caracterización de la histeria diré, muy simplificadamente, que se trata de un fracaso en la estructuración de la relación de deseo con el otro. El vacío transforma a la persona en ávida de afecto, pero nadie puede saciarle y esta avidez se convierte en destructora de la relación. Se desea amor total y al mismo tiempo no se lo puede obtener.

Si todo amor exalta al objeto para entregarse totalmente a él, en las estructuras histéricas este proceso de idealización se acentúa. La persona se entrega a un objeto idealizado con un amor platónico. Se muestra así el carácter defensivo de la idealización como protección frente al deseo sexual incestuoso, ya que el objeto primitivo de este deseo era el progenitor de distinto sexo al cual queda fijado. En la histeria masculina se idealiza a la mujer virgen, en la femenina el representante del padre es el hombre mayor de edad al que se seduce pero con el que no hay peligro de mantener relaciones sexuales. La pasión por el absoluto es típica de la posición oral, se trata de la avidez en busca del mítico objeto de vínculo que suprima toda necesidad y vacío interior. Si, como veremos, la ambivalencia del obsesivo es la del amor-odio, la del histérico se da entre el enganchamiento ávido y la decepción por el vínculo, la absorción y el rechazo, calor y frío, lleno y vacío. Todas estas claves permitirían interpretar númerosos elementos en el seno del "cristianismo exultante" de la tradición mística, incluidos los fenómenos de conversión histérica tan típicos en las apariciones (p.e. los estigmas, desvanecimientos, alucinaciones, estados hipnóticos, etc.).

\section{LOS MECANISMOS DE LA NEUROSIS}

Es sobre todo en un escrito de 1896 donde Freud conceptualiza específicamente el tema de la esencia y mecanismos de la neurosis obsesiva ("Nuevas observaciones sobre las neuropsicosis de defensa"). Respecto de su esencia dice: "La esencia de la neurosis obsesiva puede encerrarse en una breve fórmula: las representaciones obsesivas son reproches transformados, retornados de la represión, y referentes siempre a un acto sexual de la niñez ejecutado con 
placer" (O.C. I, 289. cito las obras completas en la edición de Biblioteca Nueva).

En el texto citado se supone el origen de la neurosis obsesiva en un conflicto psíquico en el que ha actuado una defensa (la represión) frente a una experiencia de placer infantil intolerable que resulta traumática. El fracaso de la defensa y el retorno de lo reprimido como afecto libre hace que éste sea desplazado sobre determinadas representaciones y actos que devienen compulsivos, es decir, acompañados de unos sentimientos que no les corresponden originalmente sino que tienen sus raíces en la historia infantil del sujeto.

Freud considera siete pasos fundamentales en la formación del síntoma:

a) La señal de angustia: señal de alarma ante la emergencia del conflicto psíquico, precediendo siempre a la entrada en acción del mecanismo neurótico de la represión.

b) Represión pulsional: es la defensa específica contra la angustia provocada por lo intolerable de una determinada pulsión, cuya sola emergencia es vivida por el sujeto como amenaza para su propia seguridad psíquica.

c) Retorno de lo reprimido: ante el fracaso de la represión los contenidos psíquicos previamente excluidos de la conciencia tienden a emerger de nuevo a este plano, siquiera sea de forma desplazada o indirecta.

d) Formación sustitutiva: como consecuencia del retorno de los contenidos reprimidos aparece ya en el plano de la conciencia un verdadero objeto sustitutivo para que a través de él pueda ser derivada la pulsión insatisfecha porque reprimida. Este objeto sustitutivo será el síntoma que, aunque de una forma patológica va a propiciar una cierta descarga de la pulsión. Por eso, al síntoma se le va a denominar también formación sustitutiva del verdadero objeto adecuado, pero imposible para la descarga de esa pulsión. La formación sustitutiva es el resultado del fracaso de la represión. Dado que la instancia superyoica sigue prohibiendo la satisfacción directa de la pulsión intolerable, se hace necesaria la aparición del síntoma como cristalización de ese objeto sustitutivo que buscamos para la pulsión.

e) Formación de compromiso: cumple en el proceso patógeno una doble función: la de satisfacer simultáneamente la pulsión y la defensa, todo ello contra la directa descarga de esa misma pulsión. Esta es la esencia de todo conflicto psíquico: una pulsión que tiende a satisfacerse mediante la descarga y una resistencia que se opone a tal descarga. Cada una de estas tendencias queda parcialmente satisfecha. La obsesión por la limpieza del obsesivo satisface a la vez la pulsión anal de entrar en contacto con la suciedad y los deseos 
compulsivos de limpieza que el individuo ha estructurado como formación reactiva frente a sus más profundos deseos de suciedad.

d) Sobredeterminación: son múltiples las formaciones de compromiso que confluyen en un sólo síntoma puesto que éstos se hallan multideterminados por la incidencia transaccional de varios conflictos. No basta con seguir una sola linea regresiva en la búsqueda de la etiología última del síntoma, sino que hay que tener en cuenta que éste se halla sobredeterminado, son múltiples los conflictos y consiguientes formaciones transaccionales que sostienen la actividad sintomática.

e) Significación del síntoma: todo síntoma neurótico es a la vez la expresión fantasmática y simbólica de la solución transaccional dada al conflicto psíquico o a la múltiple determinación del mismo.

\section{LA NEUROSIS OBSESIVA}

Freud consideró imprescindible para la caracterización de las neurosis la determinación del tipo de pulsión que subyace, los momentos de fijación y los mecanismos básicos que se ponen en marcha a partir del fracaso de la represión y el retorno de lo reprimido y de la modalidad sintomática en que tales contenidos adoptan su formación de compromiso.

\section{a) Tipo de pulsión:}

Intensa fijación en la etapa anal-retentiva, las pulsiones son sádico-anales. Confluyen en ella elementos coprófilos y agresivos. La tendencia al contacto con la suciedad y el manejo agresivo de la misma es la característica fundamental de este tipo de pulsión. La zona erógena es el ano y la actividad de la cual el niño obtiene placer es la retención de los contenidos fecales. Acompaña una historia de masturbación anal más o menos encubierta. La masa fecal es usada como estimulante de las terminaciones nerviosas por la retención, evacuación lenta, expulsión parcial o rítmica y la retracción o expulsión forzada y rápida. No es extraño que en los síntomas obsesivos aparezcan los contenido anales de forma simbólica: obsesión por cerrar el gas (ventosidad intestinal), puertas (esfínteres), fobia a la suciedad (objeto anal)... La retención es debida a la valoración de las producciones anales. Se las idealiza equiparándolas al dinero y oro. Todo lo que se guarda se revaloriza. La tendencia a retener se observa en el coleccionismo, ahorro, dificultad para desprenderse de cosas... La misma idea obsesiva cuesta de ser expulsada. Así en el caso del hombre de las ratas estudiado por Freud. 
La ambivalencia y sadismo son características esenciales de la pulsión anal. La lucha por el control de los esfínteres es la ocasión para oponerse a la madre y manifestar una agresividad que está separada de los componentes eróticos y de estima. El individuo es el sujeto y objeto de su sadismo. Se tortura con rituales, escrúpulos, exigencias, dudas... Pero también "sadinizan" a los demás. La ambivalencia se muestra como odio y amor hacia el mismo objeto. El elemento de odio es reprimido pero reaparece en las llamadas fobias de impulsión: miedo a hacer daño a alguien. El hombre de las ratas tiene miedo a que le pudiera pasar algo a dos personas a las que quiere mucho (Cfr. OC. II, 1441 ss.). Padecía de impulsos compulsivos como el de cortar el cuello con una navaja. Lo más llamativo era el miedo a que la tortura de las ratas le sucediera a su padre o a la muchacha a la que amaba. El paciente de Freud había acumulado una intensa ambivalencia respecto de su padre originada en su precoz sexualidad y los castigos del mismo.

"La crueldad es algo que forma parte del carácter infantil... Aún no se ha logrado realizar satisfactoriamente el análisis psicológico de este instinto, pero debemos aceptar que la impulsión cruel proviene del instinto de dominio y aparece en la vida sexual en una época en la cual los genitales no se han atribuido todavía su posterior papel. Por tanto, la crueldad predomina durante toda una fase de la vida sexual, que más tarde describiremos como organización pregenital". (OC. II, Tres ensayos... 1206p).

En la fase genital los componentes agresivos se encuentran fusionados con componentes unitivos y eróticos, en la etapa sádico-anal tal unión es todavía inexistente, por lo que estas tendencias antagónicas adquieren carácter de ambivalencia

\section{b) Funcionamiento del Yo:}

El obsesivo razona más que siente. Adquiere un buen control del lenguaje que aparece revestido de connotaciones mágicas: creen que las ideas puede tener consecuencias en el mundo real y por eso las procuran controlar. La sobrevaloración narcisista de las materias fecales como producto propio que uno puede retener se extiende a la posesión del dinero, cosas valiosas, capacidad de control, puntualidad, parsimonia, orden, disciplina...

Las defensas utilizadas por el yo frente a las pulsiones son:

- Desplazamiento: evita que los deseos relacionados con la satisfacción de las pulsiones anales se vuelvan conscientes. Se desplaza la investidura a otras representaciones anodinas pero vinculadas asociativamente con las represen- 
taciones intolerables, representación desfrazada en la conciencia de las mismas pulsiones anales y sádicas contra las cuales quiere el individuo defenderse. El desplazamiento produce el síntoma, ideas y representaciones obsesivas. Si se imponen, a pesar de su carácter absurdo, es debido a la intensidad con que han sido cargados.

- Control: el niño se identifica con la demanda de control de sus esfínteres y siente la gratificación narcisista derivada del hechur de conseguir satisfacer a sus padres. El control se convierte en el método para defenderse de las pulsiones amenazadoras. Pero es aprendido por el obsesivo bajo el signo del miedo a los padres y se entiende como sumisión aun perseguidor, entonces lleva la marca de una relación sadomasoquista. El control se convierte en tiranía y obtiene más placer de él que del trato con las personas. El obsesivo lo controla todo: las relaciones con los demás, el orden, la puntualidad, el tiempo (planifica)...

- Aislamiento ideoafectivo: se separa representación intolerable y afecto. Las ideas aparecen desafectivizadas. Esto produce un lenguaje aburrido, falto de emoción. Hablan como un libro, acumulan adjetivos, eufemismos, retuercen las expresiones...

-Formación reactiva: se genera una actitud de sentido contrario a la del deseo reprimido que se instala de forma permanente. Así aparece el amor a la limpieza, el orden, tenacidad, parsimonia.

- Anulación retroactiva: defensa secundaria contra las ramificaciones de lo que vuelve del inconsciente. Contra ello se toman medidas preventivas consistentes en rituales cada vez más complejos. El hombre de las ratas (paciente de Freud) retira una piedra porque teme que su amada se haga daño (fobia de impulsión, sadismo disfrazado) pero sintiendo que era absurdo se ve obligado a anular lo hecho retirando la piedra. Intenta neutralizar sus ideas compulsivas con diferentes fórmulas, diciéndose: "pero" acompañado de un gesto de rechazo.

- Identificación con el agresor: la educación de los esfínteres culmina en una identificación con el perseguidor (padres con exigencias sádicas). El agredido se convierte en agresor. Se intensifica la identificación con los aspectos sádicos y exigentes de los padres más que con sus aspectos protectores y contenedores.

\section{c) Relaciones de objeto:}

La relación con los padres se establece como sumisión al agresor. Se oponen pero teme el castigo. Las relaciones posteriores prolongan este patrón: se enfrentan a la autoridad como lo hacían con los padres, con la misma rabia y 
humillación. Pero con los iguales e inferiores predomina el control, las exigencias sádicas, torturan con las demandas de puntualidad, perfeccionismo, orden, etc. Se implican emocionalmente poco, porque la dependencia emocional es humillante, la espontaneidad peligrosa, se defienden de contactos afectivos.

Especialmente importante es la función del superyó infiltrado por el sadismo: tiraniza al yo que siente como injusto el trato que se le dispensa. Se reproduce entre las instancias de la personalidad la relación de exigencia vivida con los padres. El individuo se tortura para ser puntual, ordenado, limpio... El superyo no cuida sino que exige. El ideal del yo exalta la retención y contiene la identificación con el agresor ("quien bien te quiere te hará llorar", "la letra con sangre entra", serían sus lemas), la tozudería, control de emociones, eficiencia técnica, cierta pedantería, cortesía excesiva, convenciones y normas...

d) Mecanismo básico y proceso psicodinámico:

Comentaré brevemente el proceso de génesis de la neurosis obsesiva. Lo más típico de ella es la represión del afecto que acompaña a la representación patógena. El obsesivo es una persona que atrofia su dimensión afectiva e hipertrofia defensivamente su mundo intelectual (al contrario de lo que veíamos en la histeria).

El proceso psicodinámico puede ser resumido en los siguientes pasos:

- Fantasia intolerable: lo intolerable al futuro obsesivo es la experiencia placentera que la satisfacción de los componentes sádico-anales le produjeron en su momento y que es reproducida por el propio recuerdo de esa vivencia placentero o de la fantasía que recrea tales tendencias. La satisfacción de tales pulsiones resulta intolerable por su carácter esencialmente perverso. Lo que angustia al individuo es el miedo al descontrol de sus propias tendencias sádico-anales (pervertere=desparramar); o lo que es lo mismo miedo a que sus ambivalentes deseos de agresión hacia sus objeto amorosos terminen por autodestruirle.

- Defensa primaria: represión del afecto. "En la neurosis obsesiva el suceso no es olvidado; pero si despojado de su afecto y suprimidas o interrumpidas sus relaciones asociativas, quedando así aislado y no siendo tampoco reproducido en el curso del pensamiento corriente" (OC. III, 2853).

- Producción del síntoma primario: la escrupulosidad. El retorno de lo reprimido se muestra como escrupulosidad y reproches. Desde la perspectiva de la segunda tópica freudiana va a ser explicado a partir de la internalización 
por el sujeto de un superyó de extraordinaria severidad, fruto de la identificación con el agresor que estudiamos precedentemente. Tales reproches al ser fruto del fracaso de la represión se manifiestan como escrupulosidad general. El peligro que el yo teme procede del superyó. Los pasos siguientes tenderán a evitar todo afecto o sentimiento. El obsesivo bloquea su afectividad para no sentir la escrupulosidad y los autorreproches.

- Producción de síntomas transaccionales: afectos e ideas obsesivos

Estos síntomas protegen al individuo de la angustia que produce la temida emergencia de la escrupulosidad procedente de la pulsión sádico-anal. Freud resume estos síntomas en el siguiente texto: "De este modo el reproche (de haber realizado en la niñez el acto sexual de que se trate) se transforma fácilmente en vergüenza (de que otra persona lo sepa), en miedo hipocondríaco (de las consecuencias físicas de aquel acto), en miedo social (a la condenación social del delito cometido), en miedo a la tentación (desconfianza justificada en la propia fuerza moral de resistencia), en miedo religioso, etc. " (OC.I, Nuevas observaciones...291). Veamos uno por uno:

- Vergüenza: qué pensarán los otros si supieran de sus perversos deseos sádico-anales. Proyecta en los demás su propio superyó convirtiéndolos en hipercríticos.

- Miedo hipocondríaco: la enfermedad física como castigo (el miedo al SIDA sin causa justificada).

- Miedo social: miedo a los reproches, a ser acusado por cualquier delito al que el obsesivo añade siempre el componente sádico que viene de la infancia.

- Miedo a la tentación: es el miedo compulsivo al descontrol.

- Miedo religioso: la culpa, los autorreproches, el castigo, el tabú de lo instintivo convierte a la religión en el lugar común de toda neurosis obsesiva.

- Defensa secundaria: el ritual. cuando falla la defensa primaria de la represión y las defensas contra la escrupulosidad se pone en marcha la defensa secundaria con toda clase de medios preventivos que culminan en los célebres rituales o ceremoniales del obsesivo terminal. Tales medios preventivos cumplen una función intermedia entre los síntomas transaccionales de la escrupulosidad y la definitiva aparición de aquellos actos obsesivos que son los que realmente constituyen la verdadera defensa secundaria contra la pulsión sádico-anal.

"Al lado de estos sintomas transaccionales que significan el retorno de la reprimido, y con ello el fracaso de la defensa primitivamente conseguida, forma la 
neurosis obsesiva otros, de un origen totalmente distinto. El yo intenta, en efecto, defenderse de las ramificaciones del recuerdo, inicialmente reprimido, y crea en esta lucha defensiva síntomas que podríamos reunir bajo el nombre de defensa secundaria. Son estos síntomas, en su totalidad, medidas preventivas, que prestan buenos servicios en la lucha contra las representaciones y los afectos obsesivos" (OC.I, Nuevas observaciones... 291).

En el mismo artículo Freud habla de cuatro grupos de medidas defensivas:

- Medidas de penitencia (ceremoniales molestos, observaciones de números): cuando ya no se controla el difuso sentimiento de culpa y escrupulosidad, entran en acción todo tipo de ceremoniales molestos y observaciones de números tendentes a descargar los altos niveles de angustia.

- Medidas de prevención: (fobias, supersticciones, minuciosidades, incremento del síntoma primario de los escrúpulos): medidas de evitación, cuyo prototipo es el de las clásicas fobias tendentes a soslayar toda aquella circunstancia susceptible de hacer emerger la angustia.

- Miedo a delatarse (colección cuidadosa de todo papel escrito, misantropia): conecta con el delirio persecutorio y el miedo a la condenación social. El miedo social o persecutorio llevará al repliegue misantrópico y al control de todo contacto personal que él pueda vivir recelosamente como autoacusatorio.

- Aturdimiento: intento de disminución de los altos niveles de angustia mediante la absorción de bebidas alcohólicas o similares.

El obsesivo intenta evitar la angustia mediante la actuación. Esta actuación o descarga mediante la acción es lo que constituye la esencia misma de todo tipo de ritual o ceremonial obsesivo:

"El ceremonial neurótico consiste en pequeños manejos, adiciones, restricciones $y$ arreglos puestos en práctica, siempre en la misma forma o con modificaciones regulares, en la ejecución de determinados actos de la vida cotidiana. Tales manejos nos producen la impresión de meras formalidades y nos parecen faltos de toda significación. Así, aparecen también a los ojos del enfermo, el cual se muestra, sin embargo incapaz de suspender su ejecución, pues toda infracción del ceremonial es castigada con una angustia intolerable que le obliga en el acto a rectificar y a desarrollarlo el pie de la letra "(OC II,Los actos obsesivos y las prácticas religiosas... 1337).

Existen dos tipos de conductas compulsivas más o menos ritualizadas: las que tienden a evitar el núcleo patógeno (evitativas) y las encaminadas a eliminar el sentimiento de culpa (anulativas). 


\section{NEUROSIS OBSESIVA Y RELIGIÓN}

El siguiente cuadro es un resumen del paralelismo entre neurosis y religión que establece Freud en el artículo "Los actos obsesivos y las prácticas religiosas". Lo comentaré a continuación.

\begin{tabular}{|c|c|}
\hline OBSESIÓN & RELIGIÓN \\
\hline $\begin{array}{l}\text { 1. Acontecimiento psíquico precoz trau- } \\
\text { mático-instintos sexuales sádico-ana- } \\
\text { les reprimidos. }\end{array}$ & $\begin{array}{l}\text { 1. Renuncia y condena de los instintos } \\
\text { sexuales y egoistas }\end{array}$ \\
\hline $\begin{array}{l}\text { 2. Represión o defensa primaria fallida: } \\
\text { síntoma de vigilancia permanente }\end{array}$ & $\begin{array}{l}\text { 2. Represión imperfecta y necesidad de } \\
\text { una vigilancia continua: el pecado } \\
\text { acecha. }\end{array}$ \\
\hline $\begin{array}{l}\text { 3. Vuelta de la reprimido vivido como } \\
\text { tentación permanente y sensación de } \\
\text { culpa. }\end{array}$ & $\begin{array}{l}\text { 3. La vuelta de lo reprimido hace que } \\
\text { incluso los más piadosos se sientan } \\
\text { pecadores y sujetos de tentación. } \\
\text { Conciencia de culpa subsiguiente a la } \\
\text { tentación. }\end{array}$ \\
\hline $\begin{array}{l}\text { 4. Miedo al castigo y expectación angus- } \\
\text { tiosa de acontecimientos desgracia- } \\
\text { dos. }\end{array}$ & $\begin{array}{l}\text { 4. Temor permanente al castigo de Dios y } \\
\text { angustia derivada de ello. Miedo a la } \\
\text { condenación. }\end{array}$ \\
\hline $\begin{array}{l}\text { 5. Defensa secundaria contra la vuelta } \\
\text { de lo reprimido: ha de hacer esto o lo } \\
\text { otro para evitar la desgracia y por la } \\
\text { acción ritual compensar la presión } \\
\text { constante de lo reprimido (especie de } \\
\text { acting-out). }\end{array}$ & $\begin{array}{l}\text { 5. El ritualismo religioso, los actos de } \\
\text { penitencia... intentan compensar la } \\
\text { tentación de lo prohibido que siempre } \\
\text { retorna. }\end{array}$ \\
\hline $\begin{array}{l}\text { 6. Desplazamiento: se inviste el ceremo- } \\
\text { nial constituido como defensa, lo } \\
\text { nímio se convierte en importante. } \\
\text { Prohibiciones fóbicas para huir de } \\
\text { tentaciones y evitar los peligros. }\end{array}$ & $\begin{array}{l}\text { 6. La actuación del desplazamiento hace } \\
\text { que el acento recaiga sobre el cumpli- } \\
\text { miento formal de detalles y la escru- } \\
\text { pulosidad. Autotortura (vuelta de lo } \\
\text { sádico reprimido). }\end{array}$ \\
\hline $\begin{array}{l}\text { 7. Los sintomas son el resultado de un } \\
\text { pacto entre la instancia represora y lo } \\
\text { reprimido. Tienen carácter transaccio- } \\
\text { nal. }\end{array}$ & $\begin{array}{l}\text { 7. El carácter transaccional de la religión } \\
\text { se muestra en que en su nombre se } \\
\text { hacen muchas de las cosas que ella } \\
\text { misma prohibe. }\end{array}$ \\
\hline
\end{tabular}


Tanto la religión como la neurosis parten de la renuncia a la actividad de pulsiones constitucionalmente dadas. Es el punto de partida. Afirma Freud que son las pulsiones sexuales los que se reprimen en la neurosis y las egoistas en la religión. De hecho la religión colabora en el sostenimiento de la civilización al justificar la renuncia a lo pulsional que a ésta le es necesario. Sin embargo aquello a lo que se renuncia vuelve permanentemente, es decir, la represión siempre es fallida. De aquí la regresión de lo reprimido que, en la neurosis y la religión, aparece como tentación y angustia de la que no es posible librarse. Se han de realizar continuos esfuerzos para sofocar lo pulsional (la agresión, el sadismo). Así nace la defensa secundaria consistente en actos ceremoniales que adquieren un carácter absurdo: pequeños manejos, adiciones, restricciones, arreglos... puestos en práctica de una manera estereotipada. Parecen meras formalidades sin sentido pero el enfermo no puede suspender su ejecución. Cada fallo es castigado con la angustia y obligado a rectificar y desarrollarlo al pie de la letra. El ceremonial está "investido" de una carga de afecto que no le corresponde, que procede de otro lugar. Toda actividad puede convertirse en acto obsesivo complicada con adiciones y adquiriendo un ritmo dado.

El sujeto, observa Freud, que padece obsesiones y prohibiciones se conduce como si se hallara bajo la soberanía de una conciencia de culpabilidad de la cual no sabe nada. Se trata de una conciencia inconsciente de culpa originada en acontecimientos psíquicos precoces. En "Inhibición, síntoma y angustia" Freud explica que el superyó castiga con la culpa porque sabe más que el propio yo de lo que hay en el ello, es decir, los instintos sádico-anales reprimidos. De hecho la culpa forma parte de ese mismo impulso sádico: el individuo se tortura con ella. Así se satisface lo que se pretende evitar mostrándose el carácter transaccional de todo síntoma. "El superyó se conduce como si no hubiera tenido lugar represión ninguna, como si le fuera conocido el impulso agresivo en su verdadero sentido y con toda su carácter afectivo, y trata al yo de acuerdo a dicho sentido. El yo, que por un lado se sabe inocente, experimenta por otro un sentimiento de culpabilidad, y siente sobre sí una responsabilidad que no acierta a explicarse. Pero el enigma que así se plantea no es realmente tan intrincado. La conducta del superyó es muy comprensible y la contradicción que surge en el yo no nos muestra sino que ha permanecido incomunicado con el ello a consecuencia de la represión y, en cambio, totalmente abierto a las influencias del superyó" (OC. III, Inhibición, síntoma y angustia, 2851).

Cada situación nueva se presenta como ocasión para la reaparición de lo reprimido y engendra una expectación angustiosa de acontecimientos desgraciados así como el sentimiento de merecer castigo. El ceremonial constitu- 
ye una protección contra la tentación y la angustia, una distracción compulsiva, narcotizante, sobre la que se ha desplazado el afecto angustioso que procede de lo pulsional reprimido pero emergente. "A la conciencia de culpabilidad de los neuróticos obsesivos corresponde la convicción de los hombres piadosos de ser, no obstante la piedad, grandes pecadores y las prácticas devotas (rezos, jaculatorias, etc.) con las que inician sus actividades cotidianas, y especialmente toda empresa inhabitual, parece entrañar el valor de medidas de protección y defensa" (OC.II,Los actos obsesivos y las prácticas religiosas, 1340). Se trata de un conflicto sin solución. La presión del instinto requiere de continuos esfuerzos: "Al progresar la enfermedad los actos primitivamente encargados de la defensa van acercándose cada vez más a los actos prohibidos, en los cuales el instinto pudo manifestarse lícitamente en la época infantil" (Ibid.) Por ello los ceremoniales y prohibiciones van multiplicándose y volviéndose más complejos. En el caso de la religión se acumularán los actos de penitencia, la escrupulosidad y el rigorismo en el cumplimiento de las normas. Pero la duda nunca se aplacará y en las fantasías reaparecerá el componente sádico-libidinoso, como en los llamados malos pensamientos.

\section{LOS RASGOS DE LA RELIGIÓN OBSESIVA}

Voy a centrarme en la descripción del aspecto que toma la religión (cristianismo) bajo la influencia de la neurosis obsesiva.

a) Transferencia sobre Dios: adquiere Dios los rasgos de un poder anónimo ante el cual el hombre se siente culpable. Si la culpa es proyectiva, engendra la impresión de ser descubierto, de que los demás nos saben malos y despreciables, que conocen nuestras intenciones e impulsos, es Dios quien mejor acoge estas proyecciones. El escrupuloso vive bajo la mirada de Dios de tal modo que lo que canta con júbilo el salmo 139: "Yahvé tú me sondeas y me conoces, tu sabes cuando entro y me levanto... tu pones tu mano sobre mí", él lo vive con terror. Es la mirada de Dios que contempla al hombre feo del que habla Nietzsche en el Zaratustra. El hombre que para liberarse de la culpa y de su fealdad tuvo que matar a Dios porque su mirada penetrante le descubría en falta y le imponía la continua prohibición sobre el goce. A través de la lectura de "Inhibición, síntoma y angustia" comprendemos que sobre Dios recae la proyección de un superyó sádico:

"Podemos limitarnos a reconocer simplemente que en la neurosis obsesiva se constituye un superyó de extraordinaria severidad; o podemos pensar que el 
rasgo fundamental de esta afección es la regresión de la libido e intentar relacionar también con ella el indicado carácter severo del superyó. En realidad el superyó que procede del ello, no puede sustraerse a la regresión y a la defusión de instintos, que en el ello tienen efecto. No sería, pues, de admirar que en la neurosis obsesiva llegara a ser, por su parte, más duro, severo y cruel que en un desarrollo normal" (OC. III, Inhibición, sintoma y angustia, 2850).

Este superyó le da su carácter severo al dios de la religión obsesiva ante el cual se han de realizar los ceremoniales. Esta idea de un dios sádico fue captada por Nietzsche al hablar del más allá como odio a la vida que es instinto. El resentimiento y la venganza forman parte de la esencia del cristianismo y de su moral. La misma lectura hace Freud a través del estudio de la obsesión. Los valores llamados por Nietzsche ascéticos, representan la negación de lo pulsional, negación por la que la vida se pone contra la vida. Ellos constituyen la forma de afirmarse de los débiles, es decir, la negación de lo fuerte, del instinto. La represión de la agresión es la causa de la mediocridad que azota occidente y la consiguiente negación de toda jerarquía. Ella está implícita en el desarrollo de virtudes como la compasión, la humildad, el altruismo, la ascesis y el sacrificio... La negación de lo instintivo, (aquí la moral es síntoma como Nietzsche propone en la Genealogía) deja entrever lo instintivo mismo. La moral ascética deviene sadismo en su negación del goce ajeno, es decir,justamente la realización del instinto que se pretendía negar. No podía ser menos en quien no es capaz de concederse el goce propio y acumula por ello resentimiento. Para el obsesivo todo lo que produce placer se vuelve sospechoso: Dios no lo tolera. Toda afirmación propia, todo éxito es vivido como culpa. Según la lógica obsesiva sólo hay una plaza; el padre y el hijo, Dios y el hombre no pueden ocuparla conjuntamente. Por ello gozar es desposeer al padre, matarlo imaginariamente, lo que se convierte en un asesinato real según las leyes del psiquismo. Imposible entonces no contraer una deuda impagable y continuamente renovada, a menos de cederle todo. Por eso el número de los que se salva será escaso. Así se pensó durante mucho tiempo en el cristianismo. Fuera de la Iglesia no hay salvación y dentro también es escasa. Este concepto pobre de lo salvífico delata la obsesionalización de la religión. Predomina el castigo, todos están manchados con la culpa. La mancha, lo impuro es concebido como algo físico que se engancha, su origen último es lo excremencial. Es el caso del pecado original que se hereda desde Adan a cada uno de sus descendientes. Nada puede lavar la culpa y la suciedad que genera. El juicio de Dios es vivido como amenaza e incita a una mala conciencia permanente de quien se sabe, haga lo que haga, culpable (lo sabe ese superyó en comunicación secreta con el ello). Amor y odio se conjugan y 
dirigen hacia un padre idealizado y envidiado al que se quisiera desplazar (análisis freudiano del origen de la religión basada en el parricidio original que nos muestra en escena la psicologia obsesiva).

La transferencia ha operado desde el primitivo objeto: el padre interiorizado que da lugar al superyó. Este padre, como vimos, fue vivido como objeto sádico. El niño aprendió por sumisión, sometimiento masoquista, a quien fue considerado un agresor. De ahí que quepa reproducir este mismo vínculo con Dios, vivido también como perseguidor, a quien sólo cabe someterse o bien, unido a él y en su nombre, actuar sádicamente por identificación con el agresor y ejercer la violencia de forma más o menos encubierta. De aquí deriva buena parte del fanatismo cristiano que considerándose en posesión de la verdad absoluta actuó cometiendo toda la violencia que él prohibía.

b) El ritualismo: el rito quiere efectuar la unión con lo divino y para que sea verdad es necesario que la actitud presupuesta exista realmente. Pero puede privatizarse, retirarse del contexto simbólico que le da su sentido y obedecer a una lógica inconsciente. Entonces se degrada y deviene síntoma expresando una significación privada. La culpabilidad atrapa el ritual convirtiéndolo en acción cuasi-mágica. Es el paralelismo entre ceremonial neurótico y rito religioso que establece Freud. El neurótico cumple con cuidado meticuloso actos insignificantes: contar libros en un estante, caminar por las junturas de las baldosas, quitar o poner un objeto en una posición precisa... El mismo tipo de comportamientos puede encontrarse en el terreno religioso. Los detalles adquieren importancia, se racionalizan, se pierde función simbolizante, se aislan unos en relación a otros, se cumplen meticulosamente para que no surja la angustia.

El motivo central es la culpabilidad por ello el rito deviene una magia defensiva contra la punición esperada. Dado que Dios tiene la misma capacidad observadora que la instancia crítica interna, se le supone perpetuamente disgustado y el rito es instrumentalizado para conseguir apaciguarlo. Es el caso de sacramentos como la confesión donde la exposición minuciosa de todos los pecados jamás apacigua al penitente.

Además la represión del afecto (aislamiento ideoafectivo) da lugar a una exageración de la importancia de las normas que deben observarse con todo detalle y frialdad. Es el caso del fariseismo que denuncia el evangelio y que tanta carrera ha hecho en el seno del propio cristianismo. Los preceptos valen por sí mismos y están desafectivizados. Se prefieren las expresiones barrocas, el lenguaje complicado y retorcido, aburrido muchas veces. Impera el orden como formación reactiva y la rigidez. Así los propios rituales se convierten en castigo que tranquiliza la conciencia: la persona se tortura para ser puntual, 
rezar, cumplir preceptos, hacer penitencias... y "sadiniza" a los demás con las mismas exigencias. La tradición está hipervalorizada: lo antiguo contiene la verdad formando parte de la valoración que hace el obsesivo de la retención de objetos (el coleccionismo, el ahorro...): esta retención da lugar a productos que se revalorizan y que crecen por acumulación. Esta es la concepción de los rituales y la tradición en la iglesia católica y ortodoxa. Están cargadas las normas y rituales con una investidura que corresponde a las representaciones intolerables y ha sido desplazado sobre elementos anodinos. Así se explica su carácter compulsivo y absurdo, el culto al detalle y la falta de espíritu en la lectura de las normas litúrgicas y en la interpretación de las tradiciones.

c) Legalismo: la ambivalencia se deja notar en la relación con la ley. Cumpliéndola en extremo se demuestra su tiranía excesiva y se la ridiculiza. Esta ironía expresa la revuelta inconsciente que se alberga bajo la esclavitud aceptada. Hay que empujar la ley hasta sus exigencias extremas por acallar el menor movimiento de libertad peligrosa y garantizar por rigurosa sumisión que el amor es total. Es el caso de la casuística moral. Pero aún así no se desplaza la angustia y domina el sentimiento de no arrepentirse de verdad: el sujeto sabe inconscientemente que guarda tras sí el odio, los deseos de transgresión. Así al fiel le asaltan ideas obscenas, imagina al Cristo desnudo en la cruz con el pene erecto... Se percibe el gozo secreto de la transgresión.

La moral cristiana refleja en su vertiente ascética su cariz sádico. Bajo la idea de buscar el bien y la salvación del otro se le agrede con exigencias y normas escrupulosas, con el imperativo de controlar las malas inclinaciones o los malos pensamientos. Estas normas nacen de un superyó que está infiltrado por el sadismo del ello. El superyó comunica con el ello y obtiene una satisfacción sádica de tiranizar y torturar el yo. La relación entre las tres instancias de la tópica es fundamentalmente una relación sadomasoquisma. Sin embargo el aspecto sádico de esta relación es bastante egosintónico. El superyó detecta el sadismo y la sexualidad perversa (analidad) del ello y juzga, critica y castiga al individuo por tener estas tendencias. De esta actividad de juzgar y criticar el superyó obtiene una satisfacción de su sadismo. Sin embargo como el yo vive en la formación reactiva respecto a estas tendencias pulsionales, habitualmente siente que es injusto el trato que le da su superyó y se revuelve contra él. Así se reproduce entre las instancias de la personalidad la relación de exigencia, revuelta y castigo que el individuo vivió en su infancia entre él y sus padres. Por ello idealizan a los padres que pegan para que sus hijos vayan por el buen camino ("quien bien te quiere te hará llorar").

La identificación con este superyó se traduce en un funcionamiento sádico: muchos obsesivos defienden la pena de muerte y la eficacia pedagógica $y$ 
reformadora de los castigos... Identificados con el superyó se sienten aliviados de su propia autotortura. Se idealiza la disciplina, la obediencia ciega, la planificación, el control de las emociones, el sacrificio, la tenacidad... todo ello como agresión dirigida al otro. A los obsesivos les agrada controlar y manipular la vida de los demás. En la relación con los superiores éstos se convierten en representantes de los padres de la educación de los esfínteres y el obsesivo siente hacia ellos rabia, humillación y miedo del sadismo que les atribuye. Igual que con los padres en la infancia, su actitud respecto de los superiores oscila entre la obediencia y la rebeldía. Obedece las órdenes incluso al pie de la letra, pero les encuentra errores y falta de sentido. Es el gran dilema del obsesivo: el miedo a que se le ataque en su mala conducta y se le castigue le lleva a obedecer pero esta obediencia es vivida como una humillación y un abandono de sus verdaderos deseos lo que le produce ira. El miedo que proviene del desafio, conduce a la obediencia, en tanto que la ira, que proviene de la obediencia, conduce nuevamente al desafio. Este conflicto procede de la infancia y se expresa en términos infantiles. Obediencia y desafío se equiparan a la sumisión humillante y al asesinato. Los debates pierden su proporción. La puntualidad, pulcritud, orden, cumplimiento estricto de las obligaciones se derivan del temor a la autoridad. De igual modo otro conjunto de rasgos obsesivos proviene del elemento colérico del conflicto: obstinación, negligencia, sadismo... se dejan derivar del enojo desafiante. De aquí la curiosa mezcla de elementos contradictorios que se encuentran en los obsesivos. Estos deben defenderse de sentimientos tan intensos reduciendo al máximo sus contactos emocionales.

Respecto de los iguales y subordinados, el sadismo y la necesidad de controlar la relación hace que tiranicen a sus hijos y subordinados. Dicen que quieren que hagan las cosas perfectas y en realidad quieren que las hagan a su manera. Normalmente dan mucha importancia a detalles que a otros les parecen accesorios. Cuando la situación lo permite pueden ser bastante crueles, normalmente con la excusa de hacer el bien, educar correctamente, salvar de peligros...

Freud realiza un trabajo similar al que pretendía Nietzsche en La genealogía de la moral. Se trata de restablecer el origen de la moral, el paisaje que la ha visto nacer en orden a determinar "el valor de los valores", es decir, lo que ellos significan para la vida, la perspectiva, el sujeto que habla a través de ellos. Y en los orígenes está el instinto de agresión, el odio a la vida.

d) Narcisismo: se sufre de perfeccionismo. El nivel de exigencia interno es elevado: "Sed perfectos como perfecto es vuestro padre celestial". Se desea la perfección en la lucha contra los instintos y los deseos. Pero quererse per- 
fecto es una manera narcisista de ligarse a sí mismo. Se trata de la contradicción en la que incurre el publicano de la parábola evangélica que quiere reconocerse pecador para no ser fariseo y que por ello se afirma más perfecto que el fariseo. Perfección es deseo de suprimir todo fallo y responder al deseo del otro. Para ello se necesita la conformidad con el propio ideal del yo que se proyecta como exigencia en los demás. Como este ideal es el de la perfección como operación anti-libido, entonces se suprime el polo del devenir. El hombre querría ser enteramente lo que él imagina que debe llegar a ser. Deseo de plenitud en la que estaría totalmente de acuerdo con uno mismo. Deseo de no desear para no padecer la falta que el deseo implica. Las pulsiones son las que nos hacen caer en la cuenta de nuestra precariedad. Bajo la idea de perfección se oculta una imaginaria representación del hombre que estaría libre de la extraña alteridad de lo pulsional y máxime en el obsesivo donde lo pulsional es, básicamente, lo perverso anal-sádico.

El narcisismo se deriva de la sensación de superioridad moral que procede de la renuncia y el sacrificio. Esta sensación convierte sus actuaciones masoquistas de renuncia en virtudes éticas que devienen por ello dificilmente modificables. Otra fuente de narcisismo consiste en la alianza con un individuo o entidad que le devuelva la sensación de omnipotencia inicial que correspondía a la asociación del bebé y la madre, quien parecía ser omnisciente, omnipotente y providencia universal. Esta alianza no necesita ser con un individuo, puede ser con un sistema de pensamiento, religión o doctrina... Si separamos al individuo de su compañero omnipotente resultará abrumado por sentimientos de impotencia, inadecuación y dependencia. La grandiosidad del obsesivo depende de este tipo de asociaciones. De ahí la necesidad para el religioso obsesivo de una iglesia poderosa que dé seguridad y satisfaga sus necesidades encubiertas de dependencia.

No es difícil reconocer en esta versión del cristianismo la religión que durante mucho tiempo ha dominado occidente promoviendo la fobia frente a lo corporal, la escrupulosidad, el legalismo y la renuncia masoquista... Aunque no tengo duda de que no es la única versión posible ni de hecho lo ha sido, fue la hegemónica durante siglos. Sin embargo es probable que los problemas vayan hoy por otros caminos y que el llamado resurgir de lo sagrado obedezca a otros planteamientos más cercanos a lo que al principio del trabajo planteaba como religiosidad histérica u oral. 


\section{BIBLIOGRAFÍA}

1. FreIXAs, Jordi. Psicopatologia psicoanalítica, El model Freud-Abraham, Ed.Columna, Barcelona 1997.

2. Vergote, A., Dette et désir. Deux axes chrétiens et la dérive pathologique. Editions du seuil, Paris 1978.

3. Villamarzo, Pedro, Cursos sistemáticos de formación psicoanalítica, v.III Ed. Marova, Madrid 1991.

4. TARNAS, Richard, La pasión del pensamiento occidental, Barcelona 1997.

5. Freud, S., Obras completas. Biblioteca Nueva, Madrid 1996.

6. MaCKInNon, Roger, Psiquiatria clínica aplicada, Interamericana, Barcelona.

PEDRo MAZA

Estudio Teológico Agustiniano Valladolid 